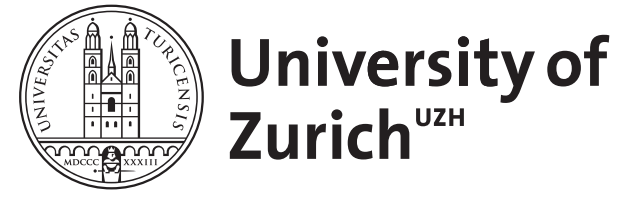

Zurich Open Repository and Archive

University of Zurich

University Library

Strickhofstrasse 39

CH-8057 Zurich

www.zora.uzh.ch

Year: 2014

Sex differences in aggression amongst children from low and high gender inequality backgrounds: A comparison of gender role and sexual selection theories

Nivette, A ; Eisner, M ; Malti, T ; Ribeaud, D

DOI: https://doi.org/10.1002/ab.21530

Posted at the Zurich Open Repository and Archive, University of Zurich

ZORA URL: https://doi.org/10.5167/uzh-166412

Journal Article

Accepted Version

Originally published at:

Nivette, A; Eisner, M; Malti, T; Ribeaud, D (2014). Sex differences in aggression amongst children from low and high gender inequality backgrounds: A comparison of gender role and sexual selection theories. Aggressive Behavior, 40(5):451-464.

DOI: https://doi.org/10.1002/ab.21530 
Running Head: Sex Differences in Children's Aggression

Sex Differences in Aggression amongst Children of Low and High Gender Inequality Backgrounds: A Comparison of Gender Role and Sexual Selection Theories

\author{
Amy E. Nivette, Ph.D.* \\ Nuffield College \\ New Road \\ University of Oxford \\ Oxford, OX1 1NF \\ (+44) (0) 1865278502 \\ amy.nivette@sociology.ox.ac.uk \\ Manuel Eisner, Ph.D. \\ Institute of Criminology \\ University of Cambridge \\ Tina Malti, Ph.D. \\ Department of Psychology \\ University of Toronto \\ Denis Ribeaud, Ph.D. \\ Chair of Sociology \\ Swiss Federal Institute of Technology (ETH) Zurich
}

*Corresponding Author

Acknowledgements: The authors would like to thank the Jacobs Foundation and the Swiss National Science Foundation for their continued financial support of the study. They would also like to express their sincere thanks to the children, parents, and teachers for participating in the study. Moreover, the authors are grateful to all the interviewers and undergraduate students for their help in data collection and coding. 


\begin{abstract}
It is well understood in developmental aggression research that males tend to exhibit higher levels of physical aggression than females. Yet there are still a number of gaps in our understanding of variation in sex differences in childhood aggression, particularly in contexts outside North America. A key assumption of social role theory is that sex differences vary according to gender polarization, whereas sexual selection theory accords variation to the ecological environment that consequently affects male competition (Archer, 2009; Kenrick \& Griskevicious, 2009). In the present paper we explore these contradicting theoretical frameworks by examining data from a longitudinal study of a culturally diverse sample of 863 children at ages 7-13 in Zurich, Switzerland. Making use of the large proportion of children from highly diverse immigrant background we compare the size of the sex difference in aggression between children whose parents were born in countries with low and with high levels of gender inequality. The results show that sex differences in aggression are generally larger among children with parents from high gender inequality backgrounds. However, this effect is small in comparison to the direct effect of a child's biological sex. We discuss implications for future research on sex differences in children's aggression.
\end{abstract} KEYWORDS: sex differences, aggression, gender inequality, social roles, sexual selection 


\section{Sex Differences in Aggression amongst Children of Low and High Gender Inequality Backgrounds: A Comparison of Gender Role and Sexual Selection Theories}

Research syntheses show that all types of direct aggression are higher in males than females across ages, countries, and measurement type (Archer, 2000, 2004, 2009; Bettencourt \& Miller, 1996; Eagly \& Steffen, 1986). However, there is an on-going debate (see Archer, 2009 and comments) on the origins of sex differences in aggression that juxtaposes two possible explanations: sexual selection theory and social role theory. Sexual selection theory proposes that these sex differences are rooted in biological processes that were shaped by greater male reproductive competition in comparison to females during human evolution (Archer, 2006, 2009). Social role theorists, in contrast, argue that sex differences in aggression are culturally determined and emerge from differential socialization into gender roles; males are taught to be aggressive and competitive, whereas females are taught to be domestic and compassionate (Eagly, 1997).

These two views lead to different hypotheses about the extent of group-level variation in the size of the sex difference of aggression: According to social role theory sex differences in aggression are primarily subject to social forces, and they should therefore be larger amongst children and adolescents who were socialized by parents from cultures with a high level of gender polarization (Wood \& Eagly, 2010). Sexual selection theory emphasizes the biological roots, shared by all human societies, of sex differences in human aggression. To the extent that variation exists it is explained as a result of variation to the ecological environment that affects the intensity of male competition (Archer, 2009; Kenrick \& Griskevicious, 2009). 
In the present paper we explore these contradicting hypotheses by examining data from a longitudinal study of a culturally diverse sample of 863 children at ages 7 to 13 in Zurich, Switzerland. Making use of the high proportion of children with an immigrant background we compare the size of the sex difference in three subtypes of aggression (physical, proactive, and reactive) between children who were socialized by parents born in countries with either low or high levels of gender inequality (thereafter GI). Furthermore, we assess the extent to which cultural variation in the size of sex differences is limited to aggressive behavior or whether it generalizes to other types of behavior, such as nonaggressive delinquent conduct, attention deficit hyperactivity disorder, and prosociality.

\section{Gender Differences in Aggression}

In a seminal paper Archer (2004) distinguished two primary theories to explain sex differences in aggression: social role theory and sexual selection theory (for more detailed reviews see, Archer, 2006; Archer, 2009 and comments; Wood \& Eagly, 2010, 2012). Social role theory focuses on the process of socialization and gender roles in forming sex differences in aggressive behavior (Eagly, 1997; Eagly, Wood, \& Diekman, 2000). In its original social constructionist version, social role theory (Eagly, 1987) posits that the societal division of labor creates stereotypical gender roles that socialize women into domestic roles that emphasize nurturing and compassion, whereas men are socialized into "breadwinner" (Archer, 2009, p. 252) roles that encourage dominance and competition (Eagly et al., 2000). Therefore, social role theory expects that the sex difference in aggression is greater the more unequal societies are in respect of women's rights. The mediating mechanism is differential socialization into a compliant, subordinate and gentle role for girls and a dominant, 
5

5

competitive and aggressive role for boys. ${ }^{1}$ In subsequent revisions Wood and Eagly (2010, 2012) incorporate some evolutionary arguments into social role theory and propose a biosocial model. Accordingly, they argue that physical differences in size, strength, and reproductive traits facilitate a division of labor that is subsequently expressed in gender roles (Wood \& Eagly, 2012). Evolved differences in body characteristics (sexual dimorphism) therefore explain the presence of stereotypical gender roles across most human cultures, while cultural, social or economic conditions explain the variability in the size of sex differences (Archer, 2009). According to this version of social role theory one would expect that some proportion of the sex difference in aggression is due to biological differences in strength and size. In contrast, variation in the polarization of gender roles should account for variability in the mean sex difference of aggressive behaviors across cultures.

Sexual selection theorists argue that sex differences in aggression are due to the greater evolutionary pressure on males towards overt competition for reproductive success (Archer, 2009; Geary, 2002; Trivers, 1972). Essentially, physical characteristics and behaviors evolve according to sexual selection, or reproductive success. For females, long internal gestation periods and higher parental investment lead to higher costs for direct aggressive behaviors. For males, in contrast, greater variance in reproductive success leads to greater incentives for aggressive same-sex competition.

\footnotetext{
${ }^{1}$ There is evidence that intergenerational transmission of gender roles can be stronger in immigrant than nonimmigrant families (Nauck, 1997), but more often transmission relies on a number of factors related to the parents, children, host country, and immigrant country (Inman, Howard, Beaumont, \& Walker, 2007; Kwak, 2003; Schönpflug, 2001). Nevertheless, a number of studies find that at least some degree of cultural intergenerational transmission occurs between parents and children, particularly in early childhood (e.g. Blau, Kahn, Liu, \& Papps, 2012; Dasgupta, 1998; Fernández \& Fogli, 2009; Phalet \& Schönpflug, 2001).
} 
Sexual selection theory allows for group-level variability in the sex difference of aggression. In particular, sex differences are expected to vary where ecological factors alter the conditions and resources that affect male and female competition (Archer, 2009; Daly \&

Wilson, 1988). Archer (2009) argues, for example, that violent inter-male competition should be more accentuated in social contexts where resources are very unequally distributed, where there is a greater surplus of males over females in the population, and where the absence of the state does not limit competition via bare physical strength. In this vein, Kenrick and Griskevicious (2009, p. 284) argue that cultural variation is not due to differential socialization, but to biological factors that are "triggered" by a particular ecological context.

\section{The Present Study}

A difficulty with assessing the strength of empirical evidence in support of either social role theory or sexual selection theory is that both predict variability in the extent to which males should be over-represented amongst perpetrators of aggressive behaviors. But while social role theory expects that differences in the polarization of gender roles are the main causal factor, sexual selection theory expects that variability in the conditions that make violent male competition a viable strategic option should account for variation in the sex ratio of aggression. Usually these two components are difficult to disentangle because societies with more polarized gender roles also tend to be societies with unequal distribution of resources, poor state functioning, poor social welfare protection, and rely on private protection coalitions such as gangs.

To address this issue, the present study examined data from a longitudinal study of children at ages 7 to 13 that are growing up in a Western affluent and urban context with a functioning education and welfare system, namely the city of Zurich, Switzerland. However, 
the sample comprises a large proportion of children whose parents have immigrated from societies with varying levels of gender inequality. Hence, by minimizing variation in the ecological context of child development we were in a better position to examine the effects of variation in gender role models. More particularly, social role theory predicts that the mean sex difference in aggression will be larger among children who were socialized by parents from societies with high levels of gender inequality, such as Turkey, Sri Lanka, and Serbia (Hypothesis 1). In contrast, according to sexual selection theory the sex differences in aggression should be expected to be broadly similar, as parents and their children live in an ecological context that does not typically trigger male competition characterized by high affluence and low unemployment, a high quality public school system, and a functioning welfare system with universal access to, for example, medical services.

To further explore the extent to which empirical patterns support either theory we also examine variation in the size of sex difference amongst children from low and high gender inequality backgrounds for subtypes of aggression (i.e., physical, reactive, proactive), over time from age 7 to age 13, and for non-aggressive behaviors that are co-morbid with aggression (e.g., ADHD, low prosociality, non-aggressive externalizing behaviors). Below we elaborate further on each of these research questions.

\section{Variation between subtypes of aggression}

Archer (2004) delineates four categories of aggression in his meta-analysis: overall (direct), physical, verbal, and indirect. Reflecting the majority of studies, he distinguishes physical and verbal forms of aggression as types of direct aggression, but researchers have also identified reactive and proactive aggression as forms of direct, sometimes physical aggression (Brendgen, Vitaro, Tremblay, \& Lavoie, 2001; Crick \& Dodge, 1996; Vitaro, 
Gendreau, Tremblay, \& Oligny, 1998). According to sexual selection theory the sex differences in aggression should be greater the more they involve escalated forms of physical violence (Hypothesis 2). In particular, Archer found that sex differences were absent for indirect aggression, small for verbal direct aggression, and higher for physical aggression. Since sexual selection theory expects that the exposure to high or low gender inequality has only a minimal impact on aggressive behavior, we assume that the same relative ranking should be observed in both high and low GI groups.

Although Archer does not make explicit predictions about sex differences in reactive and proactive aggression, we can apply the above logic to both subtypes of aggression. Reactive, or "hot-blooded" aggression occurs in response to perceived threats against one's physical (e.g. assault) or social (e.g. insult) integrity and to violations of fairness norms, whereas proactive, or "cold-blooded" aggression is instrumental, requiring no provocation (Brendgen et al., 2001, p. 293). Since proactive aggression involves dominating or threatening behavior, but not necessarily physicality, we would expect sex differences to be lower than physical aggression. Reactive aggression measures an individual's aggressive reaction to provocation, which may or may not involve physical violence. Therefore we also expect smaller sex differences in reactive aggression than physical aggression (see Hypothesis 2).

According to the logic of social role theory, culturally transmitted role expectations in both reactive and proactive aggression arise from expected gender-specific behaviors. Although social role theorists do not make specific predictions about types of aggression, a meta-analysis by Bettencourt and Miller (1996) suggests that sex differences are smaller among individuals who are provoked. They argue that provocation, according to the reciprocal "tit-for-tat rule" justifies the use of aggression in both males and females, "freeing" 
the latter from traditional gender roles (Bettencourt \& Miller, 1996, p. 422). Thus, social role theory may imply that sex differences for reactive aggression are smaller than other forms of aggression (Hypothesis 3).

\section{Variation by Age}

Gender role and sexual selection theory lead to different expectations regarding the variation of the size of sex differences in aggression over age: Sexual selection theory does not specify a clear developmental trajectory, although Archer (2009) provides some "broad predictions" regarding change throughout adolescence. Specifically, he predicts that sex differences "would be subject to some biological developmental influence, either early in postnatal life, or at puberty; and they would be largest in young adulthood" (Archer, 2009, p. 255; see also Bjorklund \& Pelligrini, 2000). Studies have found that sex differences appear early in childhood (i.e. as young as 12 months, see Lutchmaya, Baron-Cohen, \& Raggatt, 2002) and do not appear to change significantly until boys reach the age of peak sexual activity (i.e. 18 years, Archer, 2004). As a consequence, sexual selection theory would probably not expect major change in the sex-difference of aggression between ages 7 and 13 . And since sex differences are not expected to change with accumulated social learning, variations by age should be the same for children from low and high GI backgrounds (Prediction 4).

In contrast, social role theory relies on a learning mechanism, meaning that sex differences emerge in the early years of life as children are socialized into their gendered "role", first primarily by their parents and subsequently increasingly by other adults, peers, and the media (Wood \& Eagly, 2002). We therefore believe that gender role theory would predict boys and girls from high GI backgrounds differ most in their aggressive behavior at 
the beginning of primary school, when the influence of parents and other family members is greatest, and that gender differences in aggression should become more similar to those of the host society as children are increasingly socialized in the school system (Hypothesis 5). However, it is important to note that the family and school are not monolithic social environments, and an individual's choice of peers, educational pursuits, and social activities all contribute to the overall socialization process (Bussey \& Bandura, 1999).

\section{Sex Differences in Aggression-Related Behaviors}

Finally, we compare sex differences in aggression with sex differences in related nonaggressive behaviors including non-aggressive conduct problems, attention deficits and hyperactivity, and (lacking) prosocial behaviors. These behavior domains were chosen because they are known to be highly co-morbid with aggression (Loeber, Slot, \& SouthamerLoeber, 2008). This extension of the analysis allows us to better assess whether variation in the sex-ratio between children from low and high gender inequality backgrounds is limited to behaviors believed to be mainly influenced by gender-specific socialization, or whether variation extends across a wide range of behaviors.

Historical and cross-national findings have shown that the proportion of female involvement in non-aggressive deviant behaviors (e.g. property crime) varies substantially across contexts (Campbell, Muncer, \& Bibel, 2001; Eisner, 2003; Steffensmeier, Allen, \& Streifel, 1989). Campbell et al. (2001) argue that the proportion of females involved in crime is driven by economic scarcity rather than gender inequality. They propose that economic scarcity coupled with the evolutionary aversion to dangerous situations drives females to engage in less risky criminal behaviors, such as theft, cheating, or drug dealing. Macro-level

findings tend to substantiate this claim: Steffensmeier and colleagues (Steffensmeier \& Allen, 
1996; Steffensmeier et al., 1989; Steffensmeier \& Haynie, 2000) have consistently demonstrated that female offending is not associated with gender equality, i.e. that as gender roles become more equal, women do not participate in more offending.

Thus, we do not expect substantial group-level variation in the size of the sex difference for non-aggressive externalizing behaviors such as cheating, being disobedient, or vandalizing objects (Hypothesis 6).

In contrast, sex differences in behaviors associated with attention deficit and hyperactivity disorder (ADHD) should be expected to show little variation between children from backgrounds with different levels of gender inequality. ADHD has consistently been found to have a strong genetic component, although environmental components are also involved in its aetiology (Larsson et al, 2004; Khan \& Faraone, 2006). Also, unlike assertiveness and aggressive dominance it is unlikely that symptoms of ADHD are specifically supported through gender-specific socialization in any culture (Hypothesis 7).

Finally, research has consistently found high sex differences in prosocial behavior during childhood and adolescence (e.g., Eisenberg, Spinrad, \& Sadovsky, 2006). The origins of these differences are contested: Social role theory predicts that in highly gender-polarized societies males are socialized to be dominant and competitive, while females are taught to "assume an expressive role, that is, to facilitate interpersonal harmony within the family unit. Thus to fulfil their role functions effectively, females, but not males, must be socialized to be nurturing, sympathetic, and empathic" (Eisenberg \& Lennon, 1983, p. 100). Biological and evolutionary perspectives, in contrast, argue that prosocial behavior is an evolved trait with a range of individual and group benefits for survival (Penner, Dovidio, Piliavin, \& Schroeder 2005). For example, Baron-Cohen and collaborators (2005) argue that population-level sex differences in the ability to empathize are partly rooted in neurobiological differences in brain 
functioning, in particular at the extreme end of lacking empathy and interaction skills. In this vein Cohen (2007, p. 218) argues that a higher ability for empathy and prosociality among females may have evolved during the course of human evolution because it is associated with better care giving (and hence a higher likelihood of survival of offspring) and because it helped to create social support from other females whilst engaging in care-giving for the infant. Thus, where social role theory expects variation in the sex difference due to gender inequality, sexual selection perspectives expect the impact of gender-role polarization on population-level sex differences in prosocial behavior to be relatively limited (Hypothesis 8).

\section{Method}

The data for this study come from the Zurich Project on the Social Development of Children and Youths (z-proso), a prospective longitudinal study of a cohort of children that entered one of 56 primary schools in the City of Zurich in 2004 (for a detailed overview see Eisner, Malti, \& Ribeaud, 2011). The study population consists of all children who started the first grade of public primary school in the city of Zurich in 2004/05 $(N=2,495)$. The target sample was formed by 1,675 children ( $52 \%$ male, mean age 7.5 at wave 1) in 56 randomly selected primary schools (see Eisner \& Ribeaud, 2005, 2007).

Active written parent consent was required for the first six years of participation in the study. Parents who did not wish to participate themselves were asked whether they would allow their child to participate. In year 7 of the study (age 13) the participating youths were legally old enough to give the active consent to participate on their own whereas their parents received an information letter which allowed them to proscribe their child's participation (passive consent procedure). 
This cohort of children comprises very considerable proportions of families with a migrant background. More specifically, $62.2 \%$ of the mothers and $63 \%$ of the fathers were not born in Switzerland, ${ }^{2}$ which is fairly representative of Zurich's parent population (i.e. according to school statistics, over 50 percent of parents are not native German speakers, see Eisner \& Ribeaud, 2005, p. 41). More importantly, the parents of the children in this cohort were born in a diverse sample of countries and territorial entities that in their totality comprise a considerable variation in levels of gender inequality. This includes Bosnia and Herzegovina (3.1\% of the original sample of mothers and fathers), Brazil (1.1\% of mothers, $0.7 \%$ of fathers), Dominican Republic (1.2\% of mothers, $0.7 \%$ of fathers), Italy $(2.5 \%$ of mothers, $4.1 \%$ of fathers), TFYR of Macedonia ( $2.3 \%$ of mothers, $1.9 \%$ of fathers), Portugal (6.1\% of mothers, $5.5 \%$ of fathers), Serbia and Montenegro (including Kosovo) (11.5\% of mothers, $12.1 \%$ of fathers), Spain (1.5\% of mothers, $1.7 \%$ of fathers), Sri Lanka $(5.9 \%$ of mothers and fathers), Turkey (4.5\% of mothers, $5.0 \%$ of fathers), and Germany $(4.8 \%$ of mothers, $3.4 \%$ of fathers).

On average, immigrant mothers in the present sample (see below) came to live in Switzerland in 1991 (fathers in 1989) and their mean year of birth was 1969 (fathers in 1965). By the time their children were born mothers and fathers had thus spent, on average, about 22 and 24 years in their country of origin, respectively, and 6 to 8 years in Switzerland.

\section{Data}

The present analyses rely on the data from annual teacher assessments collected in waves 1 through 7 of the study, corresponding to ages 7 through $13 .{ }^{3}$ Teacher assessments

\footnotetext{
2 These figures are based on data from wave 7 (age 13).

3 Teacher assessments were preferable over child and parent assessments because they were the most consistently administered (i.e. all 7 waves) using the same Social Behavior Questionnaire [SBQ] format (i.e.
} 
were usually completed by the same teacher in waves 1 to 3 (years 1 to 3 of primary school) and waves 4 to 6 (years 4 to 6 of primary school). Teachers completed assessments for wave 7 in the first year of secondary school, when children are streamed into different schools depending on academic performance.

The initial sample comprises all children for whom at least one teacher assessment was available in any of the seven waves between ages 7 and 13 . This was the case for $92 \%$ of the original target sample $(n=1537)$. We then limited the study sample to children who lived continuously with both biological parents from waves 1 to 7 (ages 7 to 13), and to children with parents from similarly 'high' and 'low' gender inequality backgrounds. This selection served to ensure that all children in the present study were similarly exposed to socializing influences by parents who were both either high or low in their gender inequality background. The resulting sample was 863 children.

(Table 1 about here)

\section{Measures}

\section{Outcome variables}

At each wave the Social Behavior Questionnaire developed by Tremblay, Loeber, Gagnon, Charlebois, Larivee, \& LeBlanc (1991) was administered. The instrument is a comprehensive assessment of a child's problem and prosocial behaviors. Here we include four dimensions of aggression and related problem and prosocial behaviors, i.e. aggression, attention-deficit and hyperactivity disorder [ADHD], non-aggressive externalizing behavior, and prosocial behavior. For aggression we distinguish three sub-types, namely physical,

\footnotetext{
Likert-type scale). By contrast, children were only assessed in waves 1, 2, 3, 5, and 7 using an adapted SBQ
} format for the first four waves (i.e. dichotomized yes/no format). Parents were only assessed up to wave 5 . 
proactive, and reactive aggression. Teacher responses were recorded on a five-point Likert scale ranging from 1 (never) to 5 (very often).

\section{Aggression.}

The present study includes three sub-dimensions of aggression. Proactive aggression is measured with four items (e.g. "The child scares other children to get what helshe wanted", "The child tries to dominate other children"). Cronbach's alphas ranged from .87 to .90 . Reactive aggression is measured using three items (e.g. "The child responds in an aggressive manner when teased" and "The child is aggressive when contradicted") with Cronbach's alphas ranging from .93 to .94. Four items reflect physical aggression (e.g. "The child fights", "The child attacks people") with high Cronbach's alphas (range $.89<\alpha<.92$ ). All aggression sub-types are analyzed separately as well as averaged into an overall aggression score.

\section{Attention deficit and hyperactivity disorder (ADHD).}

ADHD is measured using an 8-item scale (e.g. "The child is impulsive", "The child fidgets", "The child can’t concentrate") which has high reliability (range .94<a<.95).

\section{Non-aggressive externalizing behavior.}

Non-aggressive external behaviors are measured using two sub-scales: non-aggressive conduct disorder, which is a 4-item scale including behaviors such as stealing ("The child steals"), destroying property ("The child destroys his/her own things") and lying ("The child lies, cheats"), and oppositional/defiance disorder, which consists of two items ("This child is disobedient" and "This child ignores you"). Cronbach's alphas range from .81 to .86. 


\section{Prosocial behavior.}

Prosocial behavior is measured using 7 items (e.g. "The child helps clear up a mess", "The child stops a quarrel", "The child shares things with others"). The prosocial behavior scale has high reliability $(.91<\alpha<.93)$.

\section{Covariates.}

Sex.

Of the sub-sample of 863 children used here, there were 456 males and 407 female respondents. Males are coded as 1 , and females as 0 .

\section{Gender Inequality Index.}

For each child information was collected on the country of birth of the parents. In order to determine the degree of gender polarization in a parent's home culture, we used the Gender Inequality Index [GII] created by the United Nations Development Programme (United Nations Development Programme, n.d.). The GII measures three dimensions of gender inequality and discrimination: reproductive health, empowerment, and participation in the labor market. These three dimensions use five indicators - maternal mortality, adolescent fertility, parliamentary representation, secondary level educational attainment, and labor force participation - to create an inequality index ranging from 0 (low) to 1 (high). In 2011, the countries with the highest GII scores include Afghanistan $(\mathrm{GII}=.707)$, Mali $(\mathrm{GII}=.712)$, and India $(\mathrm{GII}=.617)$. Countries with the lowest GII score in 2011 include Sweden $(\mathrm{GII}=.049)$, Denmark $(\mathrm{GII}=.060)$, Switzerland $(\mathrm{GII}=.067)$ and Germany $(\mathrm{GII}=.085)$. 
An average of GII scores from 2000 and 2005 was assigned to each parent based on the country of their birth. ${ }^{4}$ The sample was then dichotomized at the $50^{\text {th }}$ percentile according to level of gender inequality for both male and female parents. Dichotomization is beneficial in this case because it simplifies the interpretation of interaction effects (Farrington \& Loeber, 2000).

Parents were then matched by "high" or "low" GII scores, and any children with single parents, parents of unknown origin, or parents from mixed "high" and "low" backgrounds were excluded (see Table 1). The resulting sample was $n=863$, whereby 434 children had "high GII" parents $\left(M_{\mathrm{GII}}=0.379\right)$ and 429 had "low GII" parents $\left(M_{\mathrm{GII}}=0.097\right)$ Within the low GII group, $64.1 \%$ of mothers and $68.5 \%$ of fathers are Swiss (GII $=.092$ ), $9.1 \%$ of mothers and $7.5 \%$ of fathers are German $(\mathrm{GII}=.118), 17.2 \%$ of mothers and $16.1 \%$ of fathers are Portuguese $(\mathrm{GII}=.179)$, and $3.7 \%$ of mothers and $3.5 \%$ of fathers are Spanish $(\mathrm{GII}=.118)$. Parents in the high GII group are predominantly from Serbia and Montenegro (including Kosovo) (29.7\% of mothers, $31.8 \%$ of fathers, estimated GII $=.324)$, Sri Lanka, primarily Tamil, $(17.3 \%$ of mothers, $17.1 \%$ of fathers, GII $=.447)$, Turkey $(10.8 \%$ of mothers and fathers, GII $=.515)$, Bosnia and Herzegovina $(9.2 \%$ of mothers, $7.8 \%$ of fathers, estimated GII $=.349)$, and TFYR Macedonia $(6.7 \%$ of mothers, $5.8 \%$ of fathers, estimated $\mathrm{GII}=.361)$

\footnotetext{
${ }^{4}$ GII country scores tend to be highly correlated over time. Countries that were missing GII data were calculated based on the country's Human Development Index score. Since the bivariate relationship between GII and HDI was very high ( $r=-.89)$, GII scores were estimated using the linear equation $y=b(x)+c$. Whereby $y$ is the GII score, $b$ is the unstandardized correlation coefficient between available GII and HDI scores, $x$ is the country's HDI, and $c$ is the intercept. The countries that required estimation were Angola, Djibouti, Lebanon, Nigeria, Somalia, TFYR Macedonia, Serbia and Montenegro, Bosnia and Herzegovina, and Hong Kong. According to our dichotomization, all were placed in the "high" GII group. For those parents who reported emigrating from Czechoslovakia, we used the average scores from 1995 for the Czech Republic and Slovakia.
} 
We subsequently examined whether the GII index is a valid proxy for the extent of gender-role socialization. We therefore examined differences for a number of structural and attitudinal dimensions assessed in the interviews with the primary caregiver and the child (see Table 2).

Results in Table 2 show that families differed significantly. In respect of family structure, the mothers from high GII backgrounds tended to be considerably younger (mothers' birth year: $M_{\text {High GII }}=1969.5, M_{\text {Low GII }}=1966.07, F=70.33, p<.001$ ), to have more children, and the age difference between fathers and mothers was substantially larger than in families from low gender inequality backgrounds (age difference in years: $\mathrm{M}_{\mathrm{High} \mathrm{GII}}=4.00$, $\left.M_{\text {Low GII }}=2.32, F=23.13, p<.001\right)$. Parents were also more likely to report that the mother was responsible for 100 percent of the household work $\left(M_{\text {High GII }}=31 \%, M_{\text {Low GII }}=21 \%, F=\right.$ $11.11, p<.01)$, and that in their home country their fathers made most or all of the important decisions in the household ( $\left.M_{\text {High GII }}=39 \%, M_{\text {Low GII }}=26 \%, F=12.55, p<.001\right)$.

(Table 2)

In respect of attitudinal aspects we found that parents from high GII backgrounds were considerably more likely to espouse traditional parenting values that emphasize compliance (see Table 2; e.g. teach children "to be obedient", "to work hard", "to have religious faith", $\left.M_{\mathrm{High} \mathrm{GII}}=29.45, M_{\text {Low GII }}=25.14, F=271.63, p<.001\right)$. Children from high GII families were more likely to agree with statements reflecting a cultural belief in dominant masculinity (e.g. a "real man" is "ready to fight" and "protects his family") than children from low GII families $\left(M_{\text {High GII }}=2.40, M_{\text {Low GII }}=2.21, F=54.08, p<.001\right)$.

Taken together, these preliminary analyses suggest that the GII variable captures substantial group-level differences in parental living arrangements and values as well as children's belief systems that can be expected to be associated with gender inequality. 


\section{Socio-economic status.}

In the present sample children from background with high levels of gender inequality were also much likely to come from low socio-economic [SES] background families. We therefore included SES as a control variable. SES was based on coding the caregiver's current profession; the codes were then transformed into an International Socio-Economic Index of occupational status (ISEI) score (Ganzeboom, Degraaf, Treiman, \& Deleeuw, 1992). The final SES score was standardized based on the highest ISEI score of the two caregivers.

\section{Data Analysis Strategy}

Our main interest in the present study is a comparison of the effect size of biological sex on aggression and a range of related social behaviors between children from high and low gender inequality backgrounds. Throughout the analyses we use the standardized mean difference Cohen's $d$ to estimate of effect size: ${ }^{5}$

$$
d=\frac{\left(M_{1} M_{2}\right)}{\sqrt{\left.\frac{\left(n_{1} 1\right)\left(S D_{1}\right)^{2}+\left(n_{2}\right.}{\left(n_{1}+n_{2}\right.} 2\right)\left(S D_{2}\right)^{2}}}
$$

We examine the size of the sex difference in aggression and problem behaviors in two ways. First, we split the dataset by high and low GII in order to analyze the mean sex difference in aggression across waves. This step is repeated for a combined average aggression score to gain an overall effect size for high and low GII children. Second, we

\footnotetext{
${ }^{5}$ Means, standard deviations, effect sizes, and confidence intervals are presented in full in Appendix A. Confidence intervals were calculated using the Centre for Evaluation and Monitoring's "Effect Size Calculator" (http://www.cem.org/evidence-based-education/effect-size-calculator, last retrieved on October 31, 2013).
} 
regress the combined problem behavior score onto sex, the dichotomised GII score and an interaction term (sex*GII) while holding socio-economic status fixed. Eta squared values are reported to show the relative effect size for each variable.

\section{Missing data}

Across the seven waves of teacher assessments, between $14.5 \%(\mathrm{n}=125)$ and $35.7 \%$ ( $n=308)$ of values were missing. The highest percentages of values were missing from waves $5(30.4 \%)$ and $6(35.7 \%)$. To account for missing values, we generate maximum likelihood estimates using the Expectation-Maximization [EM] method in SPSS (see Allison, 2002, pp. 19-20; Dempster, Laird, \& Rubin, 1977). We included all teacher and child assessments for problem behaviors in the procedure in order to maximize the amount of nonmissing information. Child assessments tend to be correlated with teacher assessments, so improving the efficiency of the expectation step.

All analyses were conducted using the EM imputed dataset.

\section{Results}

In preliminary analyses we examined overall sex differences across the seven behavior domains and over time. We begin by reporting the overall effect sizes of sex by problem and prosocial behavior (Table 3). With the exception of proactive aggression, there are large sex differences in aggression, prosocial, and related problem behaviors (ranging from $d=0.50$ for reactive aggression to $d=-0.88$ for prosociality).

(Table 3 about here)

Table 4 shows the standardized mean sex differences in problem behaviors for each wave. The strongest effects are seen in physical aggression, particularly in middle childhood 
$\left(d_{\text {age } 7}=0.67, d_{\text {age } 8}=0.57, d_{\text {age } 9}=0.63\right)$. Similarly, there are large sex differences in prosocial behavior in the opposite direction (ranging from $d=-0.44$ to $d=-0.66$ ).

(Table 4 about here)

Table 5 reports effect sizes for sex on problem behaviors for children from low and high GII backgrounds separately. With the exception of proactive aggression, the moderate to strong positive effects indicate that boys engage in more aggressive and problem behaviors than girls regardless of ethnicity. Again, this pattern is particularly evident for physical aggression. Further, the sex difference in proactive aggression is small, in particular for children from low gender inequality backgrounds.

(Table 5 about here)

However, it is also clear from Table 5 that the size of the sex difference varies. In waves 1 through 6 , boys from high gender inequality backgrounds are likely to be more aggressive than boys from low gender inequality backgrounds. The comparatively higher effect size indicates that the sex difference in aggression is larger amongst children with parents from unequal gender backgrounds than children with parents from more gender equal backgrounds. The sex difference in overall physical aggression for children from high gender unequal backgrounds is $d=0.64$, whereas the sex difference for children from low gender inequality backgrounds is $d=0.49\left(\Delta_{\mathrm{d}}=0.15\right)$. The largest differences between low and high GII are found in non-aggressive externalizing behaviors (overall $d$ for high GII $=0.49$, overall $d$ for low GII $\left.=0.29, \Delta_{\mathrm{d}}=0.19\right)$ and proactive aggression (overall $d$ for high $\mathrm{GII}=$ 0.23 , overall $d$ for low GII $=0.04, \Delta_{\mathrm{d}}=0.20$ ).

In wave 7, for all types of aggression this pattern reverses. For physical aggression, the effect size decreases for high GII children from $d=0.50$ at age 12 to $d=0.38$ at age 13 . By contrast, the effect increases for low GII children from $d=0.37$ at age 12 to $d=0.48$ at 
age 13. There are no similar changes for other problem behaviors or prosociality. As Figure 1 illustrates for the overall aggression score, the change is most evident for children from low gender inequality backgrounds. The patterns were relatively similar until wave 7 (age 13), when the effect size increases for low GII children.

(Figure 1 about here)

Next, we assessed the significance of gender inequality using Ordinary Least Squares regression and incorporating an interaction term (sex*GII) in the equation. Regression methods also allowed us to examine the effect of gender roles in relation to socio-economic status.

Tables 6 and 7 report the results for each social behavior (averaged across all waves), first without including SES and second with SES. It is first clear that, with the exception of proactive aggression $(\beta=.02, t=0.42, p>.10)$, sex has a strong effect on all problem and prosocial behaviors (e.g. overall aggression $\beta=.20, t=4.37, p<.001$ ). The gender inequality index also has a direct effect on aggressive behaviors. Children from high gender inequality backgrounds are more likely to engage in physical aggression $(\beta=.09, t=2.06, p<.05)$ and reactive aggression $(\beta=.15, t=3.22, p<.01)$, but not proactive aggression $(\beta=.09, t=1.92$, $p<.10)$. The effect of gender inequality on ADHD and non-aggressive externalizing behaviors disappears when SES is included in the model (ADHD: $\beta=.002, t=0.05, p>.10$; externalizing: $\beta=.02, t=0.37, p>.10)$.

(Table 6 about here)

(Table 7 about here)

The significant interaction between sex and gender inequality for aggression (see Table 6) means that the sex difference in aggressive behavior is larger among children from more gender-stratified backgrounds. Specifically, boys with high GII backgrounds display 
more overall aggression than boys from low GII backgrounds (see Figure 2). However, when

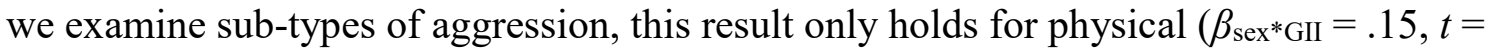
$2.77, p<.01)$ and proactive $\left(\beta_{\mathrm{sex} * \mathrm{GII}}=.15, t=2.59, p<.05\right)$ types of aggression. These interaction effects tend to hold even when accounting for a child's socio-economic status. However, sex differences in reactive aggression do not differ significantly by gender inequality background $\left(\beta_{\text {sex }^{*} \mathrm{GII}}=.03, t=0.55, p>.10\right)$.

(Figure 2 about here)

As expected, the sex difference in ADHD does not vary according to gender role socialization $\left(\beta_{\text {sex*GII }}=.06, t=1.15, p>.10\right)$. Nor does the sex difference in prosocial behaviors $\left(\beta_{\mathrm{sex} * \mathrm{GII}}=-.04, t=-0.80, p>.10\right)$. By contrast, the sex difference in non-aggressive externalizing behaviors $(\beta=.16, t=2.90, p<.01)$ is significantly larger among high GII children than low GII children.

In order to examine the size of the interaction effect in relation to sex and gender inequality, we computed partial eta squared values for sex, gender inequality, SES and the interaction term (see Table 8). Table 8 shows that, although the sex difference is larger among high GII backgrounds, the size of this effect is miniscule compared to the direct effect of sex. For aggressive behaviors, $7 \%$ of the variance in proactive aggression can be explained by sex, whereas $1 \%$ is explained by the interaction term. The difference is even starker with physical aggression: sex explains $14 \%$ of the variance, whereas gender inequality explains $4 \%$, and the interaction accounts for only $1 \%$.

(Table 8 about here) 


\section{Discussion}

We began this paper by juxtaposing the two theories of sex differentiation in aggression laid out by Archer (2004): social role theory and sexual selection theory. Social role theory proposes that sex differences in aggression will be larger where socialized gender roles are more pronounced, meaning boys are taught to be dominant and aggressive while girls are taught to be compassionate and nurturing. Sexual selection theorists argue that differences in aggression arise from hard-wired evolutionary adaptations that increase chances of successful reproduction. Due to lengthy internal gestation and higher parental investment, females have developed traits and behaviors to avoid risky confrontations that might damage reproductive success. Since males are less invested, the costs of dangerous physical confrontation is lower, leading to higher levels of (especially physical) aggression.

Our primary goal was to examine the assumptions associated with these theories. Social role theory proposes that sex differences vary according to the polarization of gender roles, and while sexual selection theory allows for environmental variability, Archer (2009) stressed that national ecological "triggers" - not socialization - account for variability. Using a sample of schoolchildren in the city of Zurich, we assessed whether the magnitude of sex differences in direct aggression varied in children whose parents are from countries with low or high gender inequality. The results show that sex differences in aggression and other problem behaviors are generally larger among children with parents from high gender inequality backgrounds (Hypothesis 1, see Table 6). However, this effect is small in comparison to the direct effect of a child's biological makeup.

In addition to examining differences in overall aggression, we explored cultural sex differences in sub-types of aggression, prosocial behavior, and related problem behaviors, i.e., ADHD and non-aggressive externalizing symptoms. As sexual selection theory predicts, 
the largest differences were seen in (the relatively more risky and dangerous behavior) physical aggression (Hypothesis 2, see Table 3). In contrast, proactive aggression has the smallest sex differences. Social role perspectives suggest that sex differences in reactive aggression are smaller than other forms because provocation "frees" females from their gender roles, justifying an aggressive response (Bettencourt \& Miller, 1996). Our results did not support this claim; among aggression sub-types, reactive aggression had the second largest gender gap after physical aggression (Hypothesis 3, see Table 3).

However, the variation in sex differences supports aspects of social role theory. Social role theory hypothesizes that males are socialized to be dominant and competitive (Wood \& Eagly, 2010). As such, where gender roles are more stratified, we would expect to see larger sex differences in dominant, physical and competitive behavior. Our results show that variation in sex differences is greatest for physical and proactive aggression, the latter of which directly measures how often the child displays dominant and threatening behaviors. Sex differences in non-aggressive externalizing behaviors were also greater among children from high gender inequality backgrounds (Hypothesis 6, see Table 7). This is likely because non-aggressive externalizing behaviors, which include stealing, defiance, and lying, are likely to be determined by cultural expectations, and so are subject to more variation across social settings.

The results for other, related problem behaviors and prosocial behavior also contribute to the theoretical discourse (Hypotheses 7 and 8, see Table 7). Interestingly, some of the largest sex differences were observed for prosocial behaviors, and not aggression. The prosocial scale used here measures how often a child is compassionate, helpful, inclusive, and resolves conflict. Both sexual selection and social role theory propose that females are more likely to be caring and compassionate, but for different reasons. However, social role theory 
also suggests females from more gender stratified backgrounds should be correspondingly more docile, compassionate and nurturing. We found that sex differences in prosocial behaviors did not vary significantly by gender role background $(\beta=-.04, t=-0.80)$.

With the exception of wave 7 , changes in sex differences over time were similar across gender inequality background (Hypothesis 4, see Figure 1). Sex differences in aggression also appear to decrease over time (Hypothesis 5, see Figure 1). However, we hesitate to draw any further conclusions based on the present results because changes may be due to a number of factors that are left unobserved in this paper, including socialization, puberty, and changes from primary to secondary school.

Overall, our data indicate that social role theory plays a small, but significant part in explaining variation in sex differences across families with different cultural backgrounds. We presented these theories as alternatives (as did Archer), but Bailey, Oxford and Geary (2009) emphasized that social role and sexual selection explanations are not mutually exclusive. Accordingly, sexual selection theory does not provide an adequate explanation as to why and how different types of aggression manifest across cultures and social structures (see also Benenson, 2009; Eagly \& Wood, 2009). Thus it is possible that social role theory may be useful for answering these questions.

\section{Limitations and Future Research}

The data used for the present analysis offered a unique opportunity to observe aggression amongst children of many different cultural backgrounds in one environment. However, there are several limitations to consider. The first is the use of the Gender Inequality Index to represent the degree of gender polarization in parents' backgrounds. The validity of this claim relies on two assumptions: that levels of inequality reflect socialization 
practices, and that parents from "low" or "high" gender inequality backgrounds consistently reinforce these practices across time. While we demonstrated that the GII is in fact related to traditional parenting values, masculine values, and gender stratified household structures (see Table 2), the latter assumption remains untested.

Research on intergenerational cultural transmission has shown that a number of factors may influence the transfer of parental cultural values to children, including the length of time in the new country, the presence of cultural networks, the degree of acculturation and assimilation, and whether the parents emigrated from an individualist or collectivist society (Kwak, 2003; Patel, Power, \& Bhavnagri, 1996; Phalet \& Schönpflug, 2001). Further, in a study of Turkish migrants in Germany, Idema and Phalet (2007) found that gender roles were more strongly transmitted from father to son than from mother to daughter. This means that gender roles are not homogeneously transmitted from parent to child, which may account for the degree of noise in the findings. Future studies can account for this by examining beliefs about gender roles and aggression in same-sex parent-child dyads.

Explanations of cultural variation in sex differences may also benefit from comparing children with specific cultural backgrounds (e.g. Turkish versus Swiss, Chinese versus Turkish, collectivist versus individualist, or Islamic versus Protestant Christian). In particular, examining the effect of cultural backgrounds - such as religion - that are not linked to a specific ecological setting (and its associated biological factors, see Kenrick \& Griskevicious, 2009) would allow researchers to distinguish potential social from biological cross-cultural variations.

Second, this paper relies exclusively on teacher assessments, which as Wood and Eagly (2010) point out, may also be influenced by cultural and gender stereotypes. In particular, teachers' beliefs about cultural stereotypes may lead them to see children of 
migrants as more aggressive "troublemakers." While we cannot rule out the possibility of teacher bias, the likelihood of teachers across all schools and grades reporting consistently higher levels of aggression for all non-Swiss boys is relatively low. Further, if teachers were reporting based on stereotypical cultural beliefs, one would expect that other "troublemaking" behaviors such as hyperactivity and disrupting class (i.e. ADHD) to also vary by gender inequality background, which is not supported by the present analysis. Nevertheless, future research should consider alternative methods of reporting behaviors, such as self-reports, peer reports, observation, and parent reports.

Third, aggression was examined on a general level because we investigated a child sample, whereas Archer (2009) distinguished between same-sex and opposite-sex aggression. Differences in inter-sex aggression, specifically partner aggression, are likely to be smaller and vary in accordance to social roles (Archer, 2006). Most of these studies are conducted using adults, so it is unknown whether opposite-sex aggression amongst children would follow similar patterns. Furthermore, critics of Archer (2009) have pointed out that his discussion of the causes of sex differences primarily refers to male-on-male within-group aggression, without consideration of inter-group aggression (Johnson \& van Vugt, 2009). Johnson and Van Vugt (2009) suggest that the exclusion of inter-group aggression in the sex difference discourse possibly misses a third causal explanation: inter-group psychology. In addition, social role theory does not comment upon sex differences in inter-group aggression. If gender roles promote male dominance and competition, Van Vugt, De Cremer, and Janssen's (2007) research on male cooperation contradicts this premise. However, if we cast the social role net more broadly, we may speculate that collectivist societies may have larger sex differences in inter-group aggression due to the cultural emphasis on prioritizing the group over the individual. 
In summary, the current study offers new evidence that the size of the sex differences in aggression amongst children varies according to gender-polarization background. Boys and girls with parents from highly gender unequal backgrounds showed larger teacherreported differences in physical and proactive aggression, but not reactive aggression. Over time, the differences between cultural backgrounds diminished, possibly due to the homogeneous socialization effect of schooling, or the shift from primary to secondary school. However, this moderating effect was small, explaining only $1 \%$ of the variation in overall aggression, whereas sex explained $7 \%$. We interpret these findings as evidence that biological differences between the sexes are more responsible for sex differences in aggression than culturally-prescribed gender roles, but that social role theory is useful for explaining some variation in the size of the sex difference. Moreover, our study points to the complexity inherent in understanding the source and manifestation of aggression in multicultural societies. While gender roles may be fading in many Western societies, immigrant parents from a more traditional background may see the need to emphasize social roles more so than if they were in their home country in order to preserve a sense of cultural identity (Nauck, 2001). Thus we find that social role theory is not antithetical to sexual selection perspectives, and instead may offer particular insight into sex differences in settings where heterogeneous socialization patterns are likely to interact. 


\section{References}

Allison (2002). Missing data, no. 136 in Quantitative Applications in the Social Sciences Sage Publications.

Antecol, H. (2000). An examination of cross-country differences in the gender gap in labor force participation rates. Labour Economics, 7(4), 409-426.

Archer, J. (2004). Sex differences in aggression in real-world settings: A meta-analytic review. Review of General Psychology, 8, 291-322.

Archer, J. (2006). Cross-cultural differences in physical aggression between partners: A social-role analysis. Personality and Social Psychology Review, 10(2), 133-153.

Archer, J. (2009). Does sexual selection explain human sex differences in aggression? [Article and Comments]. Behavioral and Brain Sciences, 32(3-4), 249-311.

Bailey, D., Oxford, J., \& Geary, D. (2009). Ultimate and proximate influences on human sex differences [Comment]. Behavioral and Brain Sciences, 32(3-4), 266-267.

Baron-Cohen, S., Knickmeyer, R. C., \& Belmonte, M. K. (2005). Sex differences in the brain: implications for explaining autism. Science, 310(5749), 819-823.

Benenson, J. (2009). Dominating versus eliminating the competition: Sex differences in human intrasexual aggression [Comment]. Behavioral and Brain Sciences, 32(3-4), 268-269.

Bettencourt, B. \& Miller, N. (1996). Gender differences in aggression as a function of provocation: A meta-analysis. Psychological Bulletin, 119(3), 422-447.

Blau, F., Kahn, L., Liu, A., \& Papps, K. (2012). The transmission of women's fertility, human capital, and work orientation across immigrant generations. Journal of Population Economics doi: 10.1007/s00148-012-0424-x. 
Brendgen, M., Vitaro, F., Tremblay, R., \& Lavoie, F. (2001). Reactive and proactive aggression: Predictions to physical violence in different contexts and moderating effects of parental monitoring and caregiving behavior. Journal of Abnormal Child Psychology, 29(4), 293-304.

Bussey, K. \& Bandura, A. (1999). Social cognitive theory of gender development and differentiation. Psychological Review, 106(4), 676-713.

Campbell, A. (2006). Sex differences in direct aggression: What are the psychological mediators? Aggression and Violent Behavior, 11, 237-264.

Campbell, A., Muncer, S., \& Bibel, D. (2001). Women and crime: An evolutionary approach. Aggression and Violent Behavior, 6, 481-497.

Cohen, D. \& Nisbett, R. (1994). Self-protection and the culture of honor : Explaining Southern violence. Personality and Social Psychology Bulletin, 20(5), 551-567.

Côté, S., Vaillancourt, T., LeBlanc, J., Nagin, D., \& Tremblay, R. (2006). The development of physical aggression from toddlerhood to pre-adolescence: A nation wide longitudinal study of Canadian children. Journal of Abnormal Child Psychology, 34(1), 71-85.

Crick, N. \& Dodge, K. (1996). Social Information-Processing Mechanisms in Reactive and Proactive Aggression. Child Development, 67(3), 993-1002.

Dasgupta, S. (1998). Gender roles and cultural continuity in the Asian Indian immigrant community in the U.S. Sex Roles, 38(11-12), 953-974.

Dempster, A.P., Laird, N.M., \& Rubin, D.B. (1977). Maximum likelihood from incomplete data via the EM algorithm. Journal of the Royal Statistical Society (Series B, Methodological), 39 (1), 1-38.

Eagly, A. (1987). Sex differences in social behavior: A social-role interpretation. Hillsdale, NJ, England: Lawrence Erlbaum Associates, Inc. 
Eagly, A. (1997). Sex differences in social behavior: Comparing social role theory and evolutionary psychology. American Psychologist, 52 (12), 1380-1383.

Eagly, A. \& Koenig, A. (2002). Social role theory of sex differences and similarities: Implication for prosocial behavior. In Dindia, K. and Canary, D. (Eds.), Sex differences and similarities in communication [2 ${ }^{\text {nd }}$ Ed.] (pp. 161-177). Mahwah, NJ: Lawrence Erlbaum Associates Publishers.

Eagly, A. \& Wood, W. (2009). Sexual selection does not provide an adequate theory of sex differences in aggression [Comment]. Behavioral and Brain Sciences, 32(3-4), 276277.

Eagly, A., Wood, W. \& Diekman, A. (2000). Social role theory of sex differences and similarities: A current appraisal. In T. Eckes \& H.M. Trautner (eds.), The developmental social psychology of gender (pp. 123-174). Mahwah, NJ: Lawrence Earlbaum Associates.

Eisenberg, N. \& Lennon, R. (1983). Sex differences in empathy and related capacities. Psychological Bulletin, 94(1), 100-131.

Eisenberg, N., Fabes, R. A., \& Spinrad, T. L. (2006). Prosocial behavior. In N. Eisenberg (Ed.), Handbook of child psychology: Vol. 3. Social, emotional, and personality development (6th ed.) (Vol. 646-718). New York: Wiley.

Eisner, M. (2003). Long-term historical trends in violent crime. Crime and Justice, 30, 83142.

Eisner, M., Malti, T., \& Ribeaud, D. (2011). Large-scale criminological field experiments: The Zurich Project on the Social Development of Children. In Gadd, D., Karstedt, S., \& Messner, S. (Eds.), The SAGE Handbook of Criminological Research Methods (pp. 410-424). London: Sage Publications. 
Eisner, M. \& Ribeaud, D. (2005). A randomised field experiment to prevent violence: The Zurich Intervention and Prevention Project at Schools, ZIPPS. European Journal of Crime, Criminal Law and Criminal Justice, 13(1), 27-43.

Eisner, M. \& Ribeaud, D. (2007). Conducting a criminological survey in a culturally diverse context: Lessons from the Zurich Project on the Social Development of Children. European Journal of Criminology, 4(3), 271-298.

Farrington, D.P. \& Loeber, R. (2000). Some benefits of dichotomization in psychiatric and criminological research. Criminal Behavior and Mental Health, 10(2), 100-122.

Fernández, R. \& Fogli, A. (2006). Fertility: The role of culture and family experience. Journal of the European Economic Association, 4(2-3), 552-561.

Ganzeboom, H., De Graaf, P., \& Treiman, D. (1992). A standard international socio-economic index of occupational status. Social Science Research, 21(1), 1-56.

Geary, D.C. (2002). Sexual selection and sex differences in social cognition. In A. McGillicuddy-De Lisi \& R. De Lisi (eds.), Biology, society, and behavior: The development of sex differences in cognition (pp. 23-54). Westport, CT: Ablex Publishing.

Inglehart, R. \& Baker, W.E. (2000). Modernization, cultural change, and the persistence of traditional values. American Sociological Review, 65(1), 19-51.

Inman, A., Howard, E., Beaumont, R., \& Walker, J. (2007). Cultural transmission: Influence of contextual factors in Asian Indian immigrant parents' experiences. Journal of Counseling Psychology, 54(1), 93-100.

Johnson, D. \& van Vugt, M. (2009). A history of war: The role of inter-group conflict in sex differences in aggression. Behavioral and Brain Science, 32(3-4), 280-281. 
Kenrick, D. \& Griskevicious, V. (2009). More holes in social roles [Comment]. Behavioral and Brain Sciences, 32(3-4), 283-285.

Khan, Sajjad A. \& Faraone, Stephen V. (2006). The genetics of ADHD: A literature review of 2005. Current Psychiatry Reports, 8(5), 393-397.

Kwak, K. (2003). Adolescents and their parents: A review of intergenerational family relations for immigrant and non-immigrant families. Human Development, 46(2-3), $15-136$.

Larsson, J. O., Larsson, H., \& Lichtenstein, P. (2004). Genetic and environmental contributions to stability and change of ADHD symptoms between 8 and 13 years of age: a longitudinal twin study. Journal of the American Academy of Child \& Adolescent Psychiatry, 43(10), 1267-1275.

Loeber, R., Slot, W., \& Southamer-Loeber, M. (2008). "Child delinquency and tomorrow's serious delinquents: Key questions addressed in this volume”. In R. Loeber, W. Slot, \& P.H. van der Laan (eds.), Tomorrow's criminals: The development of child delinquency and effective interventions (pp. 133-163). London: Ashgate Publishing.

Nauck, B. (1997). Migration and intergenerational relations: Turkish families at home and abroad. In Isajiw, W. (Ed.), Multiculturalism in North America and Europe: Comparative perspectives on interethnic relations and social incorporation (pp. 435465). Toronto: Canadian Scholar's Press.

Nauck, B. (2001). Intercultural contact and intergenerational transmission in immigrant families. Journal of Cross-Cultural Psychology, 32(2), 159-173.

Patel, N., Power, T., \& Bhavnagri, N. (1996). Socialization values and practices of Indian immigrant parents: Correlates of modernity and acculturation. Child Development, 67(2), 302-313. 
Penner, L.A., Dovidio, J.F., Piliavin, J.A., \& Schroeder, D.A. (2005). Prosocial behavior: Multilevel perspectives. Annual Review of Psychology, 56, 365-392.

Phalet, K. \& Schönpflug, U. (2001). Intergenerational transmission of collectivism and achievement values in two acculturation contexts: The case of Turkish families in Germany and Turkish and Moroccan families in the Netherlands. Journal of CrossCultural Psychology, 32(2), 186-201.

Schönpflug, U. (2001). Integenerational transmission of values: The role of transmission belts. Journal of Cross-Cultural Psychology, 32(2), 174-185.

Steffensmeier, D. \& Allan, E. (1996). Gender and crime: Toward a gendered theory of female offending. Annual Review of Sociology, 22, 459-487.

Steffensmeier, D. \& Haynie, D. (2000). Gender, structural disadvantage, and urban crime: Do macrosocial variables also explain female offending rates? Criminology, 38(2), 403438.

Steffensmeier, D., Allan, E., \& Streifel, C. (1989). Development and female crime: A crossnational test of alternative explanations. Social Forces, 68(1), 262-283.

Taylor, S.E., Klein, L.C., Lewis, B.P., Gruenewald, T.L., Gurung, R.A.R. \& Updegraff, J.A. (2000). Biobehavioral responses to stress in females: Tend-and-befriend, not fight-orflight. Psychological Review, 107(3), 411- 429.

Tremblay, R. E., Loeber, R., Gagnon, C., Charlebois, P., Larivee, S. \& LeBlanc, M. (1991). Disruptive boys with stable and unstable high fighting behavior patterns during junior elementary school. Journal of Abnormal Child Psychology, 19, 285-300.

Trivers, R. (1972). Parental investment and sexual selection. In B. Campbell (Ed.), Sexual selection and the descent of man, 1871-1971 (pp. 136-179). Chicago, IL: Aldine. 
Van den Burgh, P. (2009). Sexual selection and social roles: Two models or one? [Comment]. Behavioral and Brain Sciences, 32(3-4), 291-292.

Van Vugt, M., De Cremer, D., \& Janssen, D. (2007). Gender differences in cooperation and competition: The Male-Warrior Hypothesis. Psychological Science, 18(1), 19-23.

Vitaro, F., Gendreau, P. L., Tremblay, R., \& Oligny, P. (1998). Reactive and proactive aggression differentially predict later conduct problems. Journal of Child Psychology and Psychiatry, 39(3), 377-385.

Wood, W. \& Eagly, A. (2002). A cross-cultural analysis of the behavior of women and men: Implications for the origins of sex differences. Psychological Bulletin, 128(5), 699727.

Wood, W. \& Eagly, A. (2010). Gender. In S. Fiske, D. Gilbert, \& G. Lindzey (Eds.), Handbook of social psychology (Volume 1, $5^{\text {th }}$ Ed., pp. 629-667). Hoboken, NJ: Wiley.

Wood, W. \& Eagly, A. (2012). Biosocial construction of sex differences and similarities in behavior. In M. Zanna, P. Devine, J. Olson, \& A. Plant (Eds.), Advances in experimental social psychology (Volume 46, pp. 55-123). Oxford: Elsevier. 
Table 1

Sample Selection Process

Criteria

Gross Baseline Sample

$\mathrm{N}$

1675

At least one teacher assessment in Waves 1 through 7

1537

Both biological parents in household from ages 7-13

1072

Both parents with similar (i.e., high or low) GII background

Both biological parents from low GII backgrounds

429

Both biological parents from high GII backgrounds 
Table 2

Demographic and Socio-cultural Differences between High and Low GII Families

\begin{tabular}{|c|c|c|c|}
\hline Parent/Child Characteristics & $\begin{array}{c}\text { Low } \\
(\text { Mean GII }=.11)\end{array}$ & $\begin{array}{c}\text { High } \\
(\text { Mean GII }=.39)\end{array}$ & F-Value \\
\hline Birth year mother & $\begin{array}{c}1966.07 \\
(4.87)\end{array}$ & $\begin{array}{c}1969.5 \\
(6.08)\end{array}$ & $70.33 * * *$ \\
\hline Birth year father & $\begin{array}{c}1963.57 \\
(5.68)\end{array}$ & $\begin{array}{c}1965.49 \\
(6.38)\end{array}$ & $18.59 * * *$ \\
\hline N Siblings (wave 5) & $\begin{array}{l}1.30 \\
(0.93)\end{array}$ & $\begin{array}{c}1.71 \\
(1.39)\end{array}$ & $22.137 * * *$ \\
\hline $\begin{array}{l}\text { Traditional parenting values } \\
\text { (Parent, wave 1) }\end{array}$ & $\begin{array}{l}25.14 \\
(3.96)\end{array}$ & $\begin{array}{l}29.45 \\
(2.33)\end{array}$ & $271.63 * * *$ \\
\hline $\begin{array}{l}\text { Mother does } 100 \% \text { of household } \\
\text { work (Parent, wave 1) }\end{array}$ & $\begin{array}{l}21 \% \\
(0.41)\end{array}$ & $\begin{array}{l}31 \% \\
(0.46)\end{array}$ & $11.11 * *$ \\
\hline $\begin{array}{l}\text { Parent's father made all } \\
\text { important decisions (Parent } \\
\text { wave 3) }\end{array}$ & $\begin{array}{l}26 \% \\
(0.44)\end{array}$ & $\begin{array}{l}39 \% \\
(0.49)\end{array}$ & $12.55 * * *$ \\
\hline $\begin{array}{l}\text { Masculine Norms scale (Child, } \\
\text { wave 7) }\end{array}$ & $\begin{array}{c}2.21 \\
(0.74)\end{array}$ & $\begin{array}{c}3.40 \\
(0.75)\end{array}$ & $54.08 * * *$ \\
\hline
\end{tabular}

Note: The traditional parenting values scale is a composite scale assessed in wave 1 consisting of parent's agreement with statements such as children should "be obedient" and "have religious faith" (see Inglehart \& Baker, 2000, pp. 23-24). The masculine norms scale consists of three items measuring the child's agreement with statements such as a "real man" "protects his family", "is ready to fight", and "must defend himself" (see Cohen \& Nisbett, 1994). Calculations were performed on non-imputed data.

$* * p<.01 * * * p<.001$ 
Table 3

Means, Standard Deviations, and Cohen's d Effect Sizes for Sex on Problem Behaviors, Averaged Across all Waves

\begin{tabular}{lccccc} 
& \multicolumn{2}{c}{} & \multicolumn{2}{c}{$\begin{array}{c}\text { Confidence } \\
\text { Interval }\end{array}$} \\
\cline { 2 - 6 } Behavior Domain & Male & Female & & lower & upper \\
\hline Aggression & $0.56(0.44)$ & $0.35(0.31)$ & 0.55 & 0.41 & 0.68 \\
Physical Aggression & $0.48(0.47)$ & $0.18(0.25)$ & 0.79 & 0.65 & 0.93 \\
Proactive Aggression & $0.38(0.39)$ & $0.30(0.31)$ & 0.21 & 0.07 & 0.34 \\
Reactive Aggression & $0.91(0.59)$ & $0.64(0.49)$ & 0.50 & 0.36 & 0.63 \\
Prosociality & $2.10(0.49)$ & $2.48(0.46)$ & -0.88 & -1.02 & -0.74 \\
ADHD & $1.23(0.73)$ & $0.77(0.57)$ & 0.71 & 0.57 & 0.85 \\
Non-Aggressive & $0.34(0.32)$ & $0.18(0.23)$ & 0.56 & 0.42 & 0.69 \\
Externalizing Behavior & & & & & \\
\hline
\end{tabular}


Table 4

Cohen's d Effect Sizes for Sex on Problem Behaviors, Ages 7-13

\begin{tabular}{lccccccc} 
& \multicolumn{7}{c}{ Age } \\
Behavior Domain & 7 & 8 & 9 & 10 & 11 & 12 & 13 \\
\hline Aggression & 0.41 & 0.33 & 0.44 & 0.47 & 0.36 & 0.33 & 0.42 \\
Physical Aggression & 0.67 & 0.57 & 0.63 & 0.59 & 0.59 & 0.43 & 0.42 \\
Proactive Aggression & 0.04 & 0.01 & 0.07 & 0.27 & 0.11 & 0.17 & 0.29 \\
Reactive Aggression & 0.29 & 0.26 & 0.43 & 0.39 & 0.27 & 0.28 & 0.42 \\
Prosociality & -0.62 & -0.64 & -0.66 & -0.62 & -0.44 & -0.49 & -0.53 \\
ADHD & 0.49 & 0.43 & 0.49 & 0.68 & 0.55 & 0.57 & 0.70 \\
$\begin{array}{l}\text { Non-Aggressive } \\
\text { Externalizing Behavior }\end{array}$ & 0.31 & 0.31 & 0.42 & 0.48 & 0.41 & 0.37 & 0.44 \\
\hline
\end{tabular}


Table 5

Cohen's d Effect Sizes for Sex on Problem Behaviors, by Low/High Gender Inequality Index, Ages 7-13

\begin{tabular}{|c|c|c|c|c|c|c|c|c|c|}
\hline \multirow[b]{2}{*}{ Behavior Domain } & \multicolumn{9}{|c|}{ Age } \\
\hline & & 7 & 8 & 9 & 10 & 11 & 12 & 13 & $\begin{array}{c}\text { Mean } \\
\text { Age } 7-13\end{array}$ \\
\hline \multirow[t]{3}{*}{ Aggression } & Low GII & 0.34 & 0.25 & 0.36 & 0.38 & 0.28 & 0.24 & 0.51 & 0.34 \\
\hline & High GII & 0.49 & 0.41 & 0.53 & 0.58 & 0.44 & 0.41 & 0.38 & 0.46 \\
\hline & $\Delta$ & 0.16 & 0.16 & 0.16 & 0.19 & 0.16 & 0.17 & -0.13 & 0.12 \\
\hline \multirow[t]{3}{*}{ Physical Aggression } & Low GII & 0.60 & 0.47 & 0.51 & 0.47 & 0.51 & 0.37 & 0.48 & 0.49 \\
\hline & High GII & 0.75 & 0.67 & 0.76 & 0.71 & 0.68 & 0.50 & 0.38 & 0.64 \\
\hline & $\Delta$ & 0.15 & 0.20 & 0.25 & 0.24 & 0.17 & 0.13 & -0.09 & 0.15 \\
\hline \multirow[t]{3}{*}{ Proactive Aggression } & Low GII & -0.07 & -0.08 & -0.01 & 0.11 & -0.03 & 0.03 & 0.31 & 0.04 \\
\hline & High GII & 0.15 & 0.10 & 0.15 & 0.41 & 0.24 & 0.31 & 0.28 & 0.23 \\
\hline & $\Delta$ & 0.22 & 0.18 & 0.16 & 0.30 & 0.27 & 0.28 & -0.03 & 0.20 \\
\hline \multirow[t]{3}{*}{ Reactive Aggression } & Low GII & 0.29 & 0.24 & 0.39 & 0.38 & 0.27 & 0.24 & 0.53 & 0.33 \\
\hline & High GII & 0.30 & 0.30 & 0.48 & 0.42 & 0.29 & 0.33 & 0.35 & 0.35 \\
\hline & $\Delta$ & 0.01 & 0.06 & 0.09 & 0.05 & 0.02 & 0.09 & -0.19 & 0.02 \\
\hline \multirow[t]{3}{*}{ Prosociality } & Low GII & -0.57 & -0.60 & -0.62 & -0.61 & -0.38 & -0.44 & -0.50 & -0.53 \\
\hline & High GII & -0.69 & -0.68 & -0.70 & -0.63 & -0.51 & -0.57 & -0.58 & -0.62 \\
\hline & $\Delta$ & -0.11 & -0.08 & -0.09 & -0.02 & -0.14 & -0.14 & -0.08 & -0.09 \\
\hline \multirow[t]{3}{*}{ ADHD } & Low GII & 0.41 & 0.39 & 0.49 & 0.62 & 0.51 & 0.61 & 0.56 & 0.51 \\
\hline & High GII & 0.59 & 0.49 & 0.50 & 0.76 & 0.60 & 0.54 & 0.84 & 0.62 \\
\hline & $\Delta$ & 0.17 & 0.11 & 0.01 & 0.13 & 0.10 & -0.06 & 0.28 & 0.10 \\
\hline Non-Aggressive & Low GII & 0.18 & 0.25 & 0.32 & 0.36 & 0.31 & 0.35 & 0.29 & 0.29 \\
\hline \multirow[t]{2}{*}{ Externalizing Behavior } & High GII & 0.45 & 0.38 & 0.52 & 0.59 & 0.52 & 0.39 & 0.56 & 0.49 \\
\hline & $\Delta$ & 0.27 & 0.13 & 0.20 & 0.23 & 0.22 & 0.03 & 0.27 & 0.19 \\
\hline
\end{tabular}

Note: $\Delta=\left|\mathrm{d}_{\text {High GII }}-\mathrm{d}_{\text {Low GII }}\right|$. Numbers may not add up due to rounding. 
Table 6

OLS Regression Results for Sex, GII, SES, and Sex*GII Interaction on Aggressive Behaviors

\begin{tabular}{llcccc} 
& & \multicolumn{2}{c}{ Without SES } & \multicolumn{2}{c}{ With SES } \\
Behavior Domain & & \multicolumn{1}{c}{$\beta$} & t-value & $\beta$ & t-value \\
\hline Aggression & Sex & .20 & $4.37 * * *$ & .20 & $4.31^{* * *}$ \\
& GII & .12 & $2.64 * *$ & .05 & 1.07 \\
& Sex*GII & .12 & $2.08^{*}$ & .12 & $2.11^{*}$ \\
& SES & & & -.15 & $-3.99 * * *$ \\
Physical Aggression & & & & & \\
& Sex & .28 & $6.44^{* * *}$ & .28 & $6.40^{* * *}$ \\
& GII & .09 & $2.06^{*}$ & .03 & 0.64 \\
& Sex*GII & .15 & $2.77 * *$ & .15 & $2.81^{* *}$ \\
& SES & & & -.13 & $-3.65 * * *$ \\
Proactive Aggression & & & & & \\
& Sex & .02 & 0.42 & .02 & 0.35 \\
& GII & .09 & 1.92 & .04 & 0.78 \\
& Sex*GII & .15 & $2.59 *$ & .15 & $2.61 * *$ \\
& SES & & & -.11 & $-2.88^{* *}$ \\
Reactive Aggression & & & & & \\
& Sex & .23 & $4.90^{* * *}$ & .22 & $4.83 * * *$ \\
& GII & .15 & $3.22^{* *}$ & .07 & 1.48 \\
& Sex*GII & .03 & 0.55 & .03 & 0.57 \\
& SES & & & -.16 & $-4.39 * * *$ \\
\hline
\end{tabular}

$* p<.05 * * p<.01 * * * p<.001$ 
Table 7

OLS Regression Results for Sex, GII, SES, and Sex*GII Interaction on Prosocial and Problem Behaviors

\begin{tabular}{|c|c|c|c|c|c|}
\hline \multirow{2}{*}{\multicolumn{2}{|c|}{ Behavior Domain }} & \multicolumn{2}{|c|}{ Without SES } & \multicolumn{2}{|c|}{ With SES } \\
\hline & & $\beta$ & $\mathrm{t}$-value & $\beta$ & t-value \\
\hline \multicolumn{6}{|c|}{ Prosociality } \\
\hline & Sex & -.38 & $-8.60 * * *$ & -.38 & $-8.59 * * *$ \\
\hline & GII & -.09 & -1.88 & -.09 & -1.80 \\
\hline & Sex*GII & -.04 & -0.80 & -.04 & -0.80 \\
\hline & SES & & & -.01 & -0.13 \\
\hline \multicolumn{6}{|l|}{ ADHD } \\
\hline & Sex & .30 & $6.68 * * *$ & .30 & $6.67 * * *$ \\
\hline & GII & .11 & $2.27^{*}$ & .002 & 0.05 \\
\hline & Sex*GII & .06 & 1.15 & .07 & 1.19 \\
\hline & SES & & & -.21 & $-5.94 * * *$ \\
\hline \multicolumn{6}{|c|}{ Non-Aggressive Externalizing Behavior } \\
\hline & Sex & .18 & $3.90 * * *$ & .15 & $3.38 * * *$ \\
\hline & GII & .09 & $2.00 *$ & .02 & 0.37 \\
\hline & Sex*GII & .16 & $2.90 * *$ & .15 & $2.71 * *$ \\
\hline & SES & & & -.22 & $-6.11 * * *$ \\
\hline
\end{tabular}


Table 8

Partial Eta Squared Values for Sex, GII, SES, and Sex*GII on Problem

Behaviors

\begin{tabular}{lcccc} 
Behavior Domain & Sex & GII & Sex*GII & SES \\
\hline Aggression & .07 & .04 & .01 & \\
Physical Aggression & .14 & .04 & .01 & \\
Proactive Aggression & .01 & .03 & .01 & \\
Reactive Aggression & .06 & .03 & .00 & \\
Prosociality & .16 & .01 & .001 & \\
ADHD & .12 & .02 & .002 & \\
Non-Aggressive Externalizing Behavior & .08 & .04 & .01 & \\
& & & & \\
Aggression & & & & \\
Physical Aggression & .07 & .01 & .01 & .02 \\
Proactive Aggression & .14 & .01 & .01 & .02 \\
Reactive Aggression & .01 & .01 & .01 & .01 \\
Prosociality & .06 & .01 & .00 & .02 \\
ADHD & .16 & .01 & .001 & .00 \\
Non-Aggressive Externalizing Behavior & .08 & .01 & .01 & .03 \\
\hline
\end{tabular}




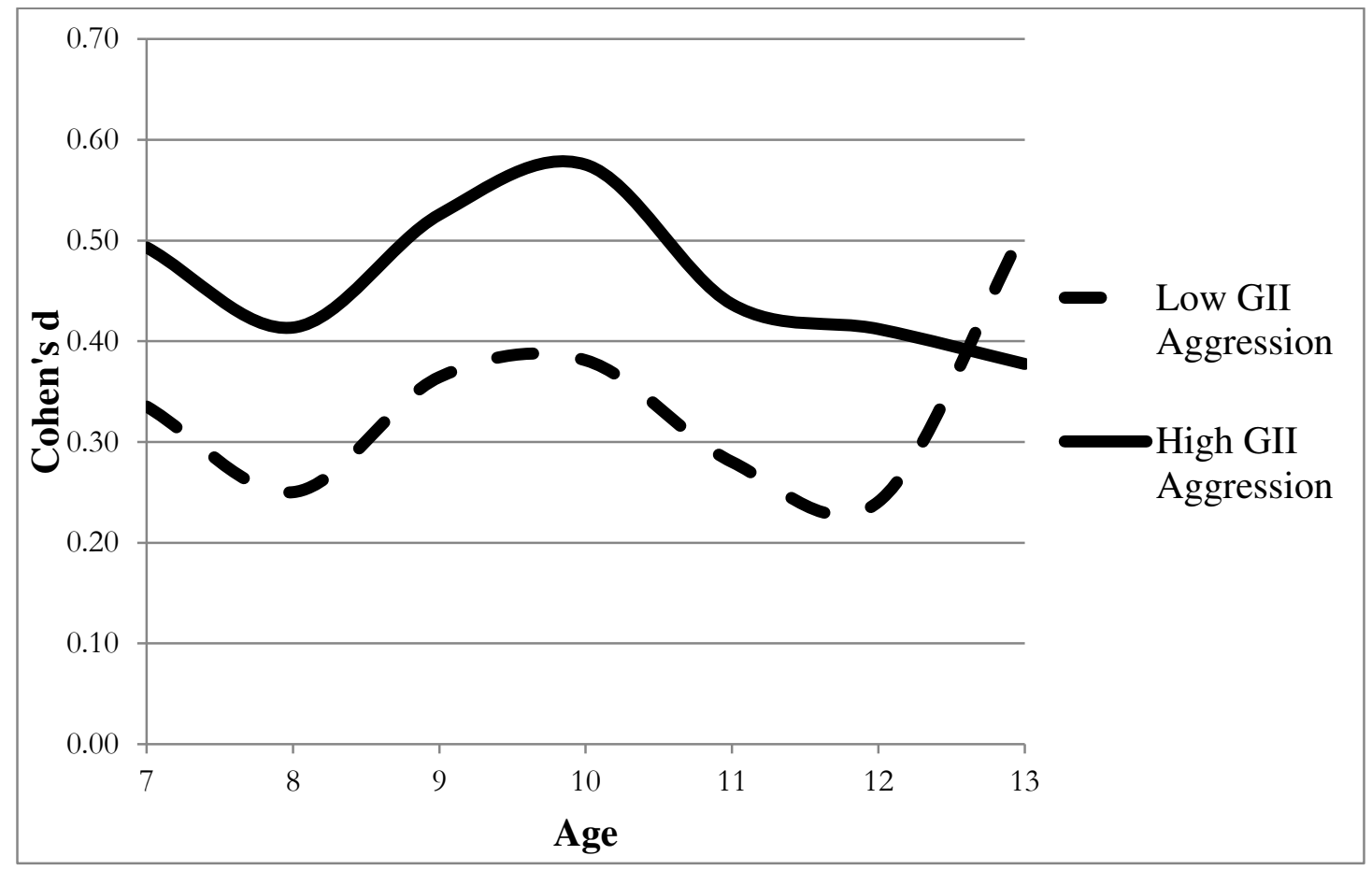

Figure 1. Standardized Mean Sex Difference Trends for Overall Aggression (Ages 7 to 13) by High and Low GII Backgrounds 


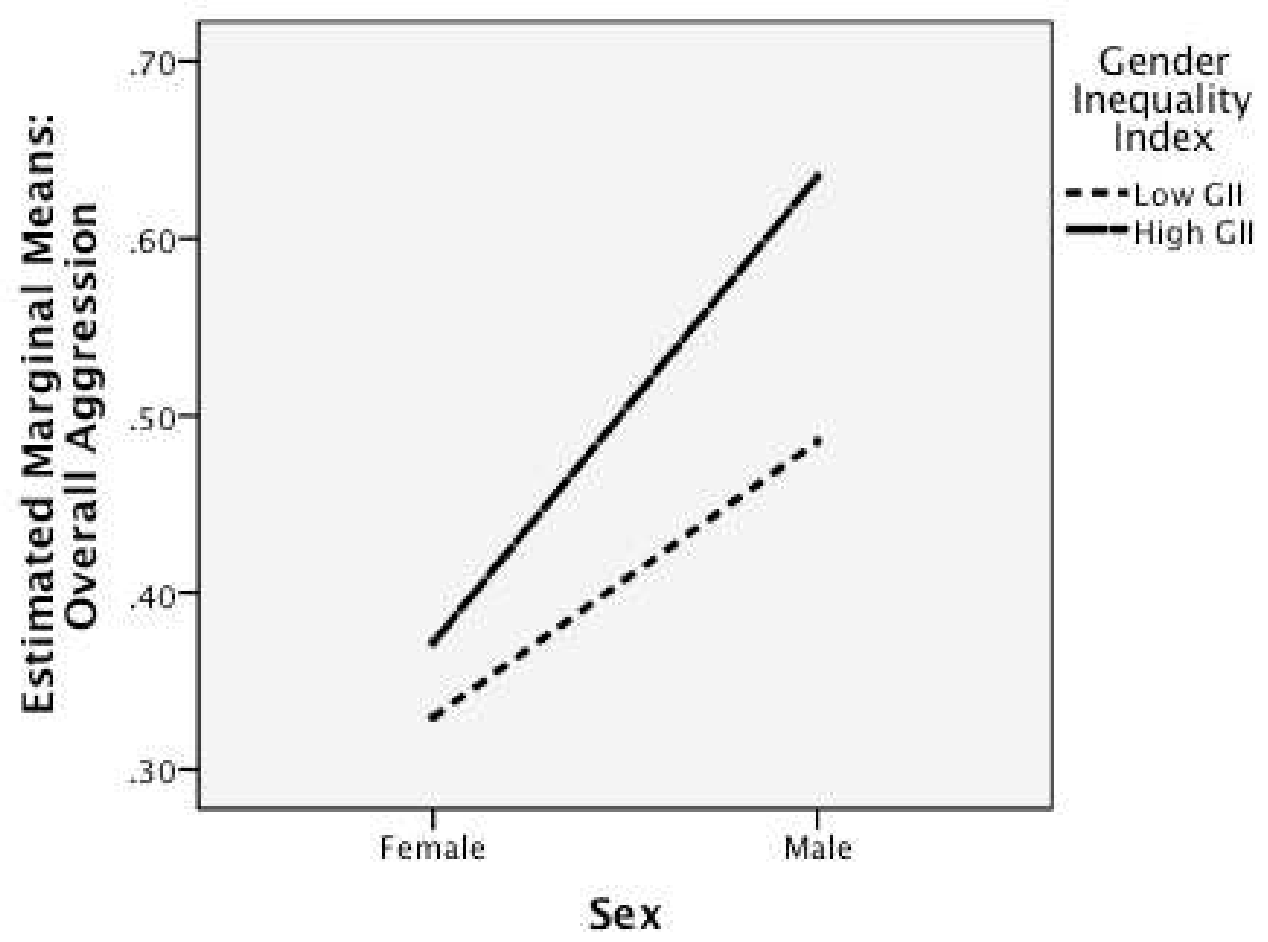

Figure 2. Estimated Marginal Means for Overall Aggression (Ages 7 to 13) by Sex and GII Background, Controlling for SES 


\section{Appendix A}

Table A.1 Means, Standard Deviations, Effect Sizes, and Confidence Intervals for All Children, Ages 7 - 13.

\begin{tabular}{|c|c|c|c|c|c|c|c|c|c|}
\hline \multirow{2}{*}{\multicolumn{3}{|c|}{ Behavior Domain }} & \multicolumn{7}{|c|}{ Age } \\
\hline & & & 7 & 8 & 9 & 10 & 11 & 12 & 13 \\
\hline \multirow[t]{5}{*}{ Aggression } & Mean (SD) & Male & $0.63(0.64)$ & $0.58(0.49)$ & $0.65(0.61)$ & $0.61(0.68)$ & $0.52(0.56)$ & $0.51(0.58)$ & $0.43(0.55)$ \\
\hline & & Female & $0.41(0.44)$ & $0.40(0.48)$ & $0.41(0.47)$ & $0.33(0.44)$ & $0.34(0.44)$ & $0.34(0.47)$ & $0.23(0.39)$ \\
\hline & Cohen's d & & 0.41 & 0.33 & 0.44 & 0.47 & 0.36 & 0.33 & 0.42 \\
\hline & $95 \% \mathrm{CI}$ & Lower & 0.28 & 0.19 & 0.30 & 0.34 & 0.22 & 0.19 & 0.29 \\
\hline & & Upper & 0.55 & 0.46 & 0.57 & 0.61 & 0.49 & 0.46 & 0.56 \\
\hline \multirow{5}{*}{$\begin{array}{l}\text { Physical } \\
\text { Aggression }\end{array}$} & Mean (SD) & Male & $0.63(0.77)$ & $0.53(0.66)$ & $0.57(0.68)$ & $0.53(0.73)$ & $0.44(0.58)$ & $0.39(0.57)$ & $0.26(0.49)$ \\
\hline & & Female & $0.21(0.41)$ & $0.22(0.41)$ & $0.21(0.42)$ & $0.18(0.37)$ & $0.16(0.33)$ & $0.17(0.40)$ & $0.09(0.31)$ \\
\hline & Cohen's d & & 0.67 & 0.57 & 0.63 & 0.59 & 0.59 & 0.43 & 0.42 \\
\hline & $95 \% \mathrm{CI}$ & Lower & 0.53 & 0.43 & 0.49 & 0.45 & 0.45 & 0.29 & 0.28 \\
\hline & & Upper & 0.81 & 0.70 & 0.76 & 0.72 & 0.73 & 0.56 & 0.55 \\
\hline \multirow{5}{*}{$\begin{array}{l}\text { Proactive } \\
\text { Aggression }\end{array}$} & Mean (SD) & Male & $0.35(0.53)$ & $0.35(0.54)$ & $0.40(0.56)$ & $0.44(0.64)$ & $0.37(0.54)$ & $0.41(0.59)$ & $0.32(0.58)$ \\
\hline & & Female & $0.33(0.49)$ & $0.35(0.52)$ & $0.36(0.50)$ & $0.28(0.48)$ & $0.32(0.49)$ & $0.32(0.50)$ & $0.17(0.39)$ \\
\hline & Cohen's d & & 0.04 & 0.01 & 0.07 & 0.27 & 0.11 & 0.17 & 0.29 \\
\hline & $95 \% \mathrm{CI}$ & Lower & -0.09 & -0.12 & -0.06 & 0.14 & -0.03 & 0.04 & 0.15 \\
\hline & & Upper & 0.18 & 0.15 & 0.20 & 0.40 & 0.24 & 0.31 & 0.42 \\
\hline \multirow{5}{*}{$\begin{array}{l}\text { Reactive } \\
\text { Aggression }\end{array}$} & Mean (SD) & Male & $1.02(0.90)$ & $0.92(0.81)$ & $1.08(0.86)$ & $0.94(0.96)$ & $0.84(0.81)$ & $0.80(0.80)$ & $0.81(0.86)$ \\
\hline & & Female & $0.77(0.76)$ & $0.71(0.79)$ & $0.74(0.75)$ & $0.59(0.76)$ & $0.62(0.75)$ & $0.58(0.76)$ & $0.48(0.69)$ \\
\hline & Cohen's d & & 0.29 & 0.26 & 0.43 & 0.39 & 0.27 & 0.28 & 0.42 \\
\hline & $95 \% \mathrm{CI}$ & Lower & 0.16 & 0.13 & 0.30 & 0.26 & 0.14 & 0.14 & 0.29 \\
\hline & & Upper & 0.43 & 0.40 & 0.57 & 0.53 & 0.41 & 0.41 & 0.56 \\
\hline
\end{tabular}


Table A.1 continued.

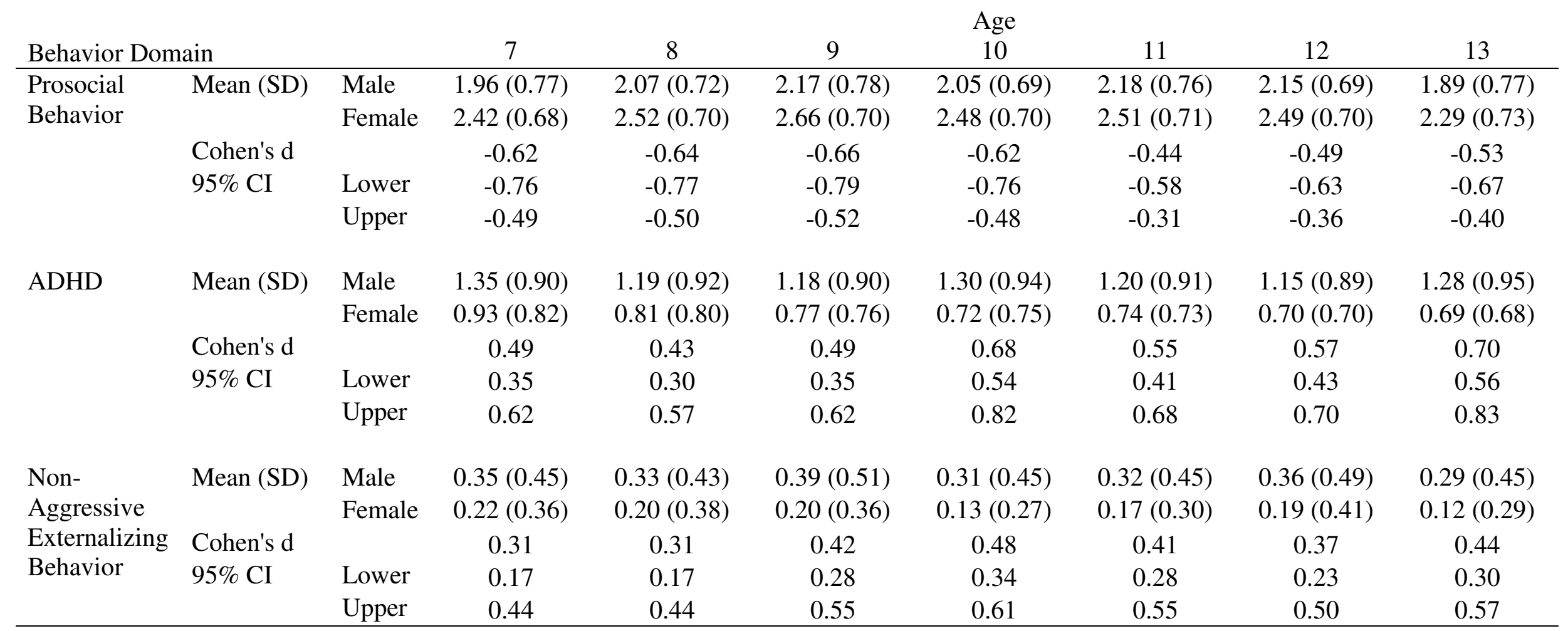

Note. $\mathrm{SD}=$ standard deviation; $\mathrm{CI}=$ confidence interval 
Table A.2 Means, Standard Deviations, Effect Sizes, and Confidence Intervals by Low/High Gender Inequality Index, Ages 7 - 13.

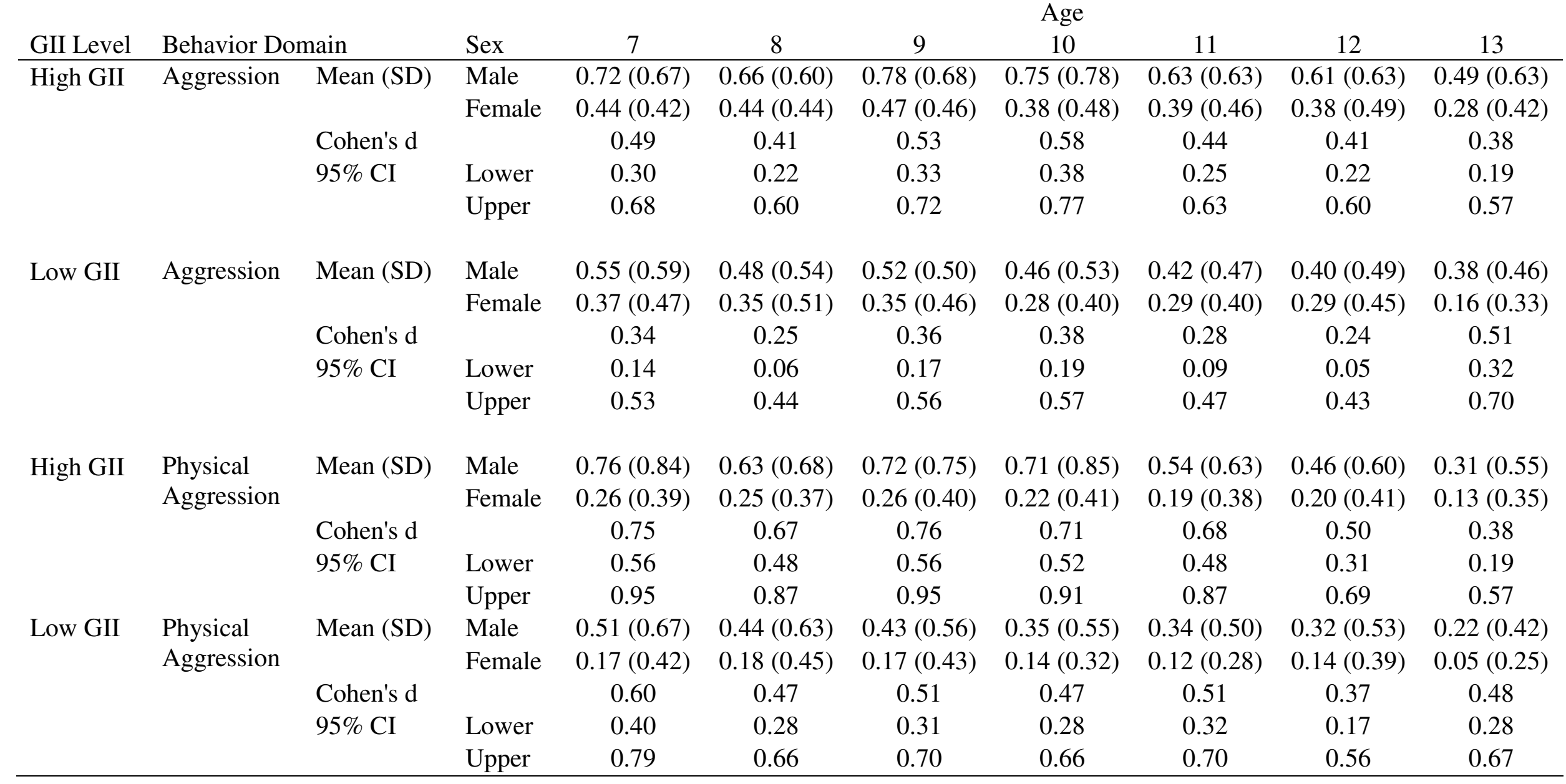


Table A.2 continued.

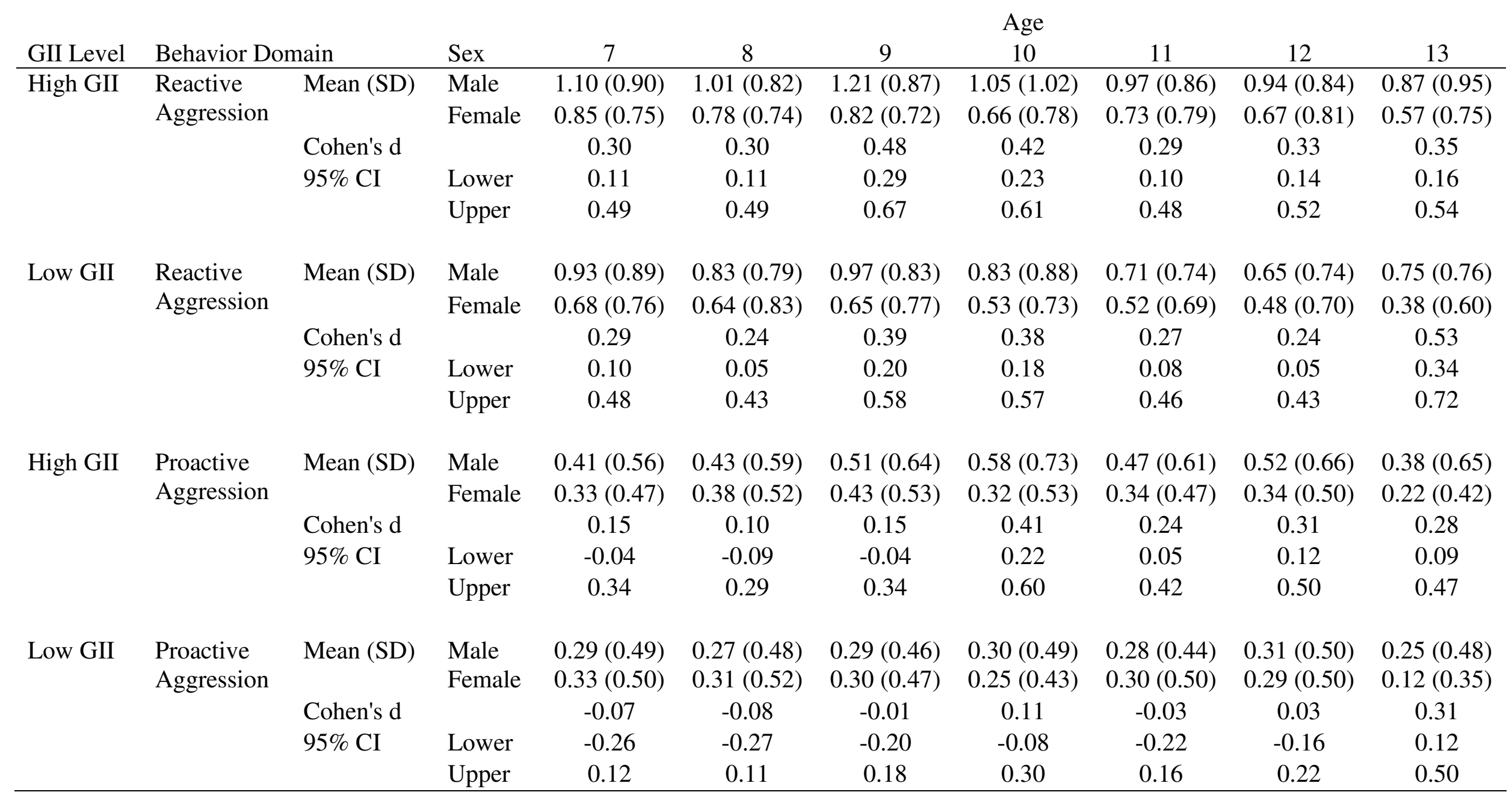


Table A.2 continued.

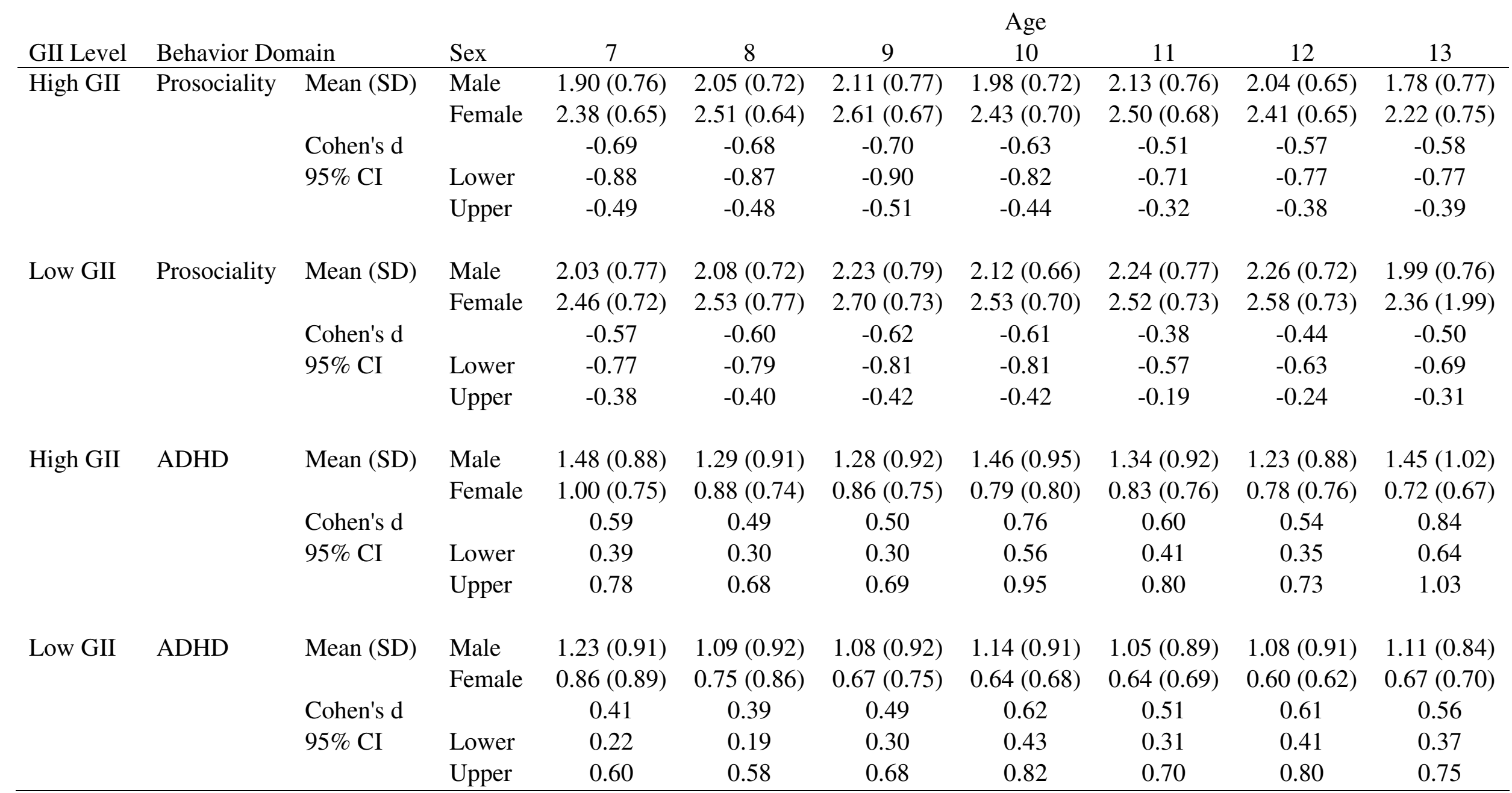


Table A.2 continued.

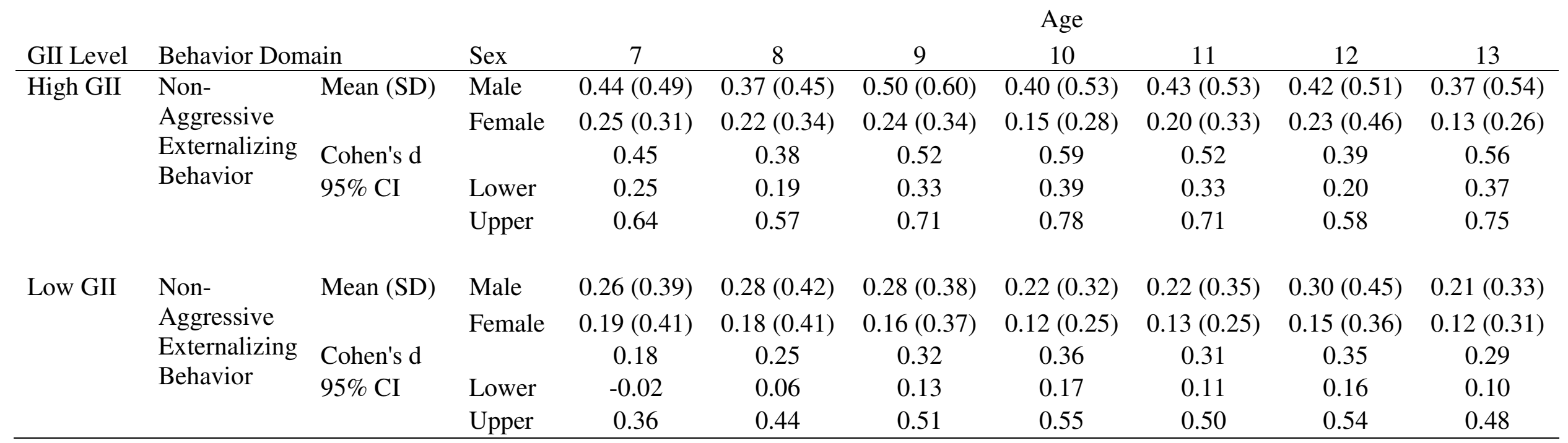

